\title{
Identification of salt gland-associated genes and characterization of a dehydrin from the salt secretor mangrove Avicennia officinalis
}

Pavithra A Jyothi-Prakash ${ }^{1,2}$, Bijayalaxmi Mohanty ${ }^{3}$,Edward Wijaya ${ }^{4}$, Tit-Meng Lim', Qingsong Lin ${ }^{1}$, Chiang-Shiong Loh ${ }^{1,2}$ and Prakash P Kumar, ${ }^{1,5^{*}}$

\begin{abstract}
Background: Salt stress is a major challenge for growth and development of plants. The mangrove tree Avicennia officinalis has evolved salt tolerance mechanisms such as salt secretion through specialized glands on its leaves. Although a number of structural studies on salt glands have been done, the molecular mechanism of salt secretion is not clearly understood. Also, studies to identify salt gland-specific genes in mangroves have been scarce.

Results: By subtractive hybridization (SH) of cDNA from salt gland-rich cell layers (tester) with mesophyll tissues as the driver, several Expressed Sequence Tags (ESTs) were identified. The major classes of ESTs identified include those known to be involved in regulating metabolic processes (37\%), stress response (17\%), transcription (17\%), signal transduction (17\%) and transport functions (12\%). A visual interactive map generated based on predicted functional gene interactions of the identified ESTs suggested altered activities of hydrolase, transmembrane transport and kinases. Quantitative Real-Time PCR (qRT-PCR) was carried out to validate the expression specificity of the ESTs identified by SH. A Dehydrin gene was chosen for further experimental analysis, because it is significantly highly expressed in salt gland cells, and dehydrins are known to be involved in stress remediation in other plants. Full-length Avicennia officinalis Dehydrin1 (AoDHN1) cDNA was obtained by Rapid Amplification of cDNA Ends. Phylogenetic analysis and further characterization of this gene suggested that AoDHN1 belongs to group II Late Embryogenesis Abundant proteins. qRT-PCR analysis of Avicennia showed up-regulation of AoDHN1 in response to salt and drought treatments. Furthermore, some functional insights were obtained by growing $E$. coli cells expressing AoDHN1. Growth of E. coli cells expressing AoDHN1 was significantly higher than that of the control cells without AoDHN1 under salinity and drought stresses, suggesting that the mangrove dehydrin protein helps to mitigate the abiotic stresses.

Conclusions: Thirty-four ESTs were identified to be enriched in salt gland-rich tissues of A. officinalis leaves. qRT-PCR analysis showed that 10 of these were specifically enriched in the salt gland-rich tissues. Our data suggest that one of the selected genes, namely, AoDHN1 plays an important role to mitigate salt and drought stress responses.
\end{abstract}

Keywords: Avicennia officinalis, Salinity, Dehydrin, Subtractive hybridization, Leaf salt glands, Drought stress

\footnotetext{
* Correspondence: dbskumar@nus.edu.sg

${ }^{1}$ Department of Biological Sciences, National University of Singapore, 14

Science Drive 4, Singapore, Republic of Singapore

${ }^{5}$ Temasek Life Sciences Laboratory, National University of Singapore, 1

Research Link, Singapore, Republic of Singapore

Full list of author information is available at the end of the article
}

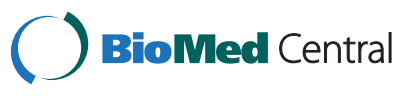

(c) 2014 Jyothi-Prakash et al.; licensee BioMed Central Ltd. This is an Open Access article distributed under the terms of the Creative Commons Attribution License (http://creativecommons.org/licenses/by/4.0), which permits unrestricted use, distribution, and reproduction in any medium, provided the original work is properly credited. The Creative Commons Public Domain Dedication waiver (http://creativecommons.org/publicdomain/zero/1.0/) applies to the data made available in this article, unless otherwise stated. 


\section{Background}

Avicennia officinalis is an obligate halophyte that has evolved both morphologically and physiologically to thrive in saline conditions [1]. Multicellular salt glands are found on $A$. officinalis leaves that help to secrete excess salt, which is one of the key adaptations leading to salt tolerance of these plants [1-6]. Some studies have shown that salt secretion is an energy dependant process [4], while others have indicated that it can occur through exocytosis $[7,8]$. Although a large number of studies have been conducted on the structure of salt glands [3,6,9-12], only a few were regarding their function [13]. Therefore, studies such as identification of genes that are specifically expressed in salt glands will contribute significantly towards resolving mangrove salt gland function.

Over the last decade many techniques have been developed to identify genes that are specifically or preferentially expressed in the tissue of interest [14-18]. Subtractive hybridization $(\mathrm{SH})$ is one such tool [19], which has been widely used in various organisms including plants $[18,20,21]$. Despite several transcriptomic studies carried out to identify genes responsible for salt tolerance in other mangroves such as Bruguiera and Aegiceras [22-24], the molecular mechanisms regulating salt secretion have not been established so far. The mangrove salt glands occur primarily on the leaf epidermis. Hence, the use of isolated epidermal peels that are salt gland-rich will increase the probability of identifying genes expressed preferentially in the glands [25]. Therefore, SH technique could be exploited to identify genes that are expressed in salt gland-rich tissues of the mangrove $A$. officinalis.

In addition to salt secretion, production of osmolytes [26-28] or specialized proteins such as Late Embryogenesis Abundant (LEA) proteins has been shown to protect macromolecules in the cells under stress [29,30]. A special class of LEA proteins (group II) known as dehydrins has been shown primarily to play important roles in alleviating salt and other abiotic stresses through their protective action by binding to macromolecules [29,31-35]. Dehydrins are intrinsically unstructured proteins that contain three conserved motifs: $\mathrm{Y}, \mathrm{S}$ and $\mathrm{K}$ and are divided into five subgroups [36]. Each subgroup has been identified to play a role in response to a specific abiotic stress condition [31]. Mangroves such as Avicennia marina have been shown to contain dehydrins [37]. Nevertheless, the role of dehydrins in mangrove salt glands has not been adequately understood yet. Although, dehydrins have been identified from mangroves such as Avicennia marina, their occurrence in salt glands and role in salt secretion have not been well explored.

In this study, we have identified differentially expressed genes in salt gland-rich leaf tissues of Avicennia officinalis using $\mathrm{SH}$ technique. We have generated a predicted functional gene interaction map of A. officinalis salt glands using the identified ESTs. Additionally, quantitative RTPCR validation of several ESTs that are preferentially expressed in the salt glands compared to mesophyll tissue has also been carried out. Here we report characterization of a Dehydrin gene (AoDHN1) identified from the SH analysis. Its expression pattern and response to salinity and drought stress treatments were studied in A. officinalis. We present data suggesting the abiotic stress-mitigating function of AoDHN1 by growing E. coli cells expressing AoDHN1 under salinity and drought stresses. Taken together, our data suggest that $A o D H N 1$ plays an important role in salt and drought stress remediation in $A$. officinalis.

\section{Results}

\section{Classification of differentially expressed ESTs and expression analysis of selected ESTs}

From the subtracted cDNA library, we identified 900 ESTs. Most of the ESTs identified could not be annotated based on function, hence they were classified as unknown and were omitted from further analysis. Among the annotated ESTs, 62 showed high $e$-values and upon removing the duplicates, 34 unique ESTs were obtained. These were then grouped under several categories (Figure 1) based on predicted functions (Table 1).

The major classes of genes obtained from $\mathrm{SH}$ corresponded to metabolism (37\%), stress response (17\%), signal transduction (17\%), transcription factor (17\%) and transporters (12\%) (Figure 1A). Genes involved in lipid, amino acid and carbohydrate metabolic pathways were identified. Among the stress responsive classes of genes, those involved in protein recycling, namely, ubiquitin conjugating enzyme and $26 \mathrm{~S}$ proteasome regulatory subunit were abundant (Table 1). The transporter genes identified included Aquaporins, ATP-Binding Cassette (ABC) transporter family, Vacuolar ATP synthase subunit and Plasma membrane $H^{+}$-ATPase. Several kinase genes, including Casein Kinase, Serine/Threonine Kinases along with GTPase were identified in the signal transduction class. NAC Domain-containing Protein 32, transcription factor R2R3, F-box 2, Salt-inducible Zinc Finger are some of the transcription factor genes that were identified in transcription factor class.

Tissue-specificity of expression of the 34 selected ESTs was verified by qRT-PCR (Figure $1 \mathrm{~B}$ and Additional file 1). $A B C$ transporter and Ribosomal protein S6 showed more than 10-fold abundance in salt gland-rich tissue compared to mesophyll tissue. A Dehydrin gene identified from $\mathrm{SH}$ (AoDHN1) showed more than 6-fold increase (Figure 1B). Of these, Dehydrin is a gene with a possible function relevant for abiotic stress tolerance. Hence, it was a preferred gene for further studies. The remaining ESTs, namely, Leucine-Rich Repeat Receptor, 3-Ketoacyl-CoA Synthase, 1-Amino-Cyclopropane-1-Carboxylate Oxidase (ACC Oxidase) and Aquaporin showed $\sim 5$-fold higher expression in 


\section{A}

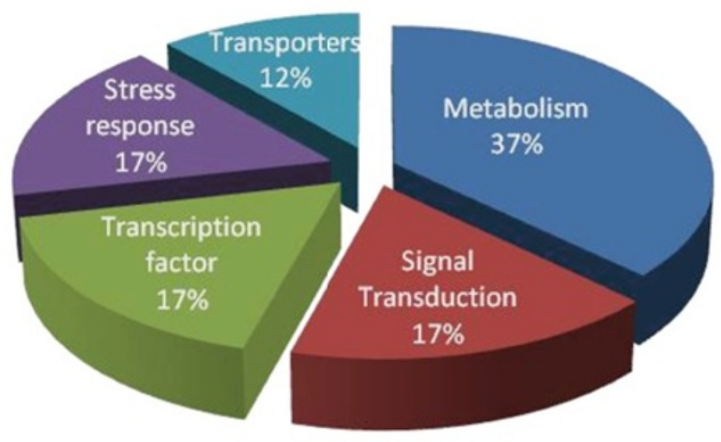

B

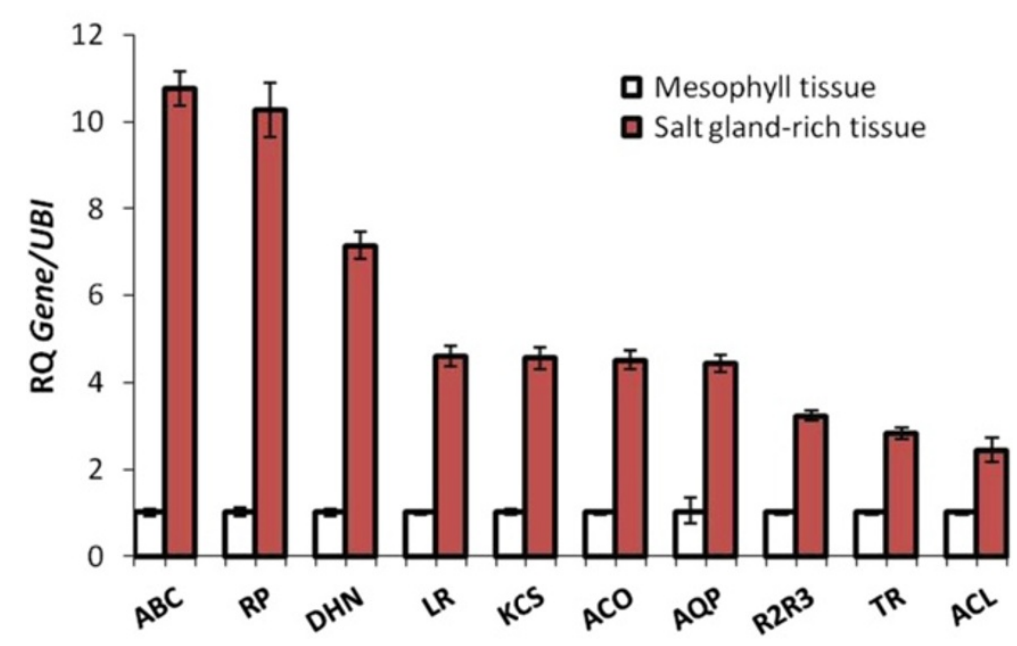

Figure 1 Classification of differentially expressed ESTs and expression analysis of selected ESTs. (A) Distribution of ESTs obtained from subtractive hybridization of salt gland rich-tissue and mesophyll tissue from A. officinalis leaves. (B) Expression profile of selected EST's enriched in salt glands by qRT-PCR analysis of transcripts from mesophyll tissue vs. salt gland rich-tissue. White-brown-complex ABC transporter family (ABC), Ribosomal protein S6 (RP), Dehydrin (DHN), Leucine-rich repeat protein kinase (LR), 3-ketoacyl-CoA synthase (KCS), 1-aminocyclopropane-1-carboxylate oxidase (ACO), Aquaporin (AQP), Transcription factor R2R3 (R2R3), Thioredoxin H (TR), ATP Citrate Lyase (ACL) RQ - Relative quantification (mean $\pm S E, n=3)$.

the salt gland-rich tissue. $R 2 R 3$ transcription factor, Thioredoxin $H$ and ATP Citrate Lyase showed about 3- to 4-fold higher expression in the salt gland-rich tissue. Expression analyses of other ESTs which showed no significant differential expression are provided in Additional file 1.

\section{Functional gene-network analysis of the ESTs identified from Subtractive Hybridization}

An interactive REVIGO (REduce VIsualize Gene Ontology) graph that indicates the functional network of the identified ESTs was generated [38]. The overview of this graph shows a functional gene network in salt gland-rich tissue generated against Arabidopsis cDNA library. At the center of the network, a tight cluster of interaction between hydrolase, ATPase and transmembrane transport activity is depicted (Figure 2A). Transmembrane transport activity seemed to be coupled with ATPase and hydrolase activities. Ligase activity is seen further down the gene network, especially the activity of ubiquitin-protein ligase. Although extensive transmembrane transport and hydrolase activities seem to be occurring in a narrow-range, transferase activity, nucleic acid binding and sequencespecific DNA binding transcription factor activities were also observed.

Similarly, the interactive graph developed by comparison with poplar cDNA database also highlights ATPase, hydrolase and transmembrane transport activities (Figure 2B). A tight cluster of these three activities was observed but with lower intensity. In parallel, tiny clusters of nucleic acid binding and metal ion binding activities were observed. Magnesium ions, alkali metal ion, potassium ion, cation binding activities were major ion binding clusters. However, sequence-specific DNA binding, nucleotide-, nucleoside- and ATP-binding were included in the nucleic acid binding clusters. An additional small binding cluster of phosphotransferase that are involved in kinase activity was also observed. 
Table 1 Avicennia officinalis ESTs identified from salt gland-rich tissue after subtractive hybridization

\begin{tabular}{|c|c|c|c|c|c|}
\hline $\begin{array}{l}\text { Avicennia clone ID and } \\
\text { classification }\end{array}$ & Putative function & $O_{f}$ & $\begin{array}{l}\text { Reference organism } \\
\text { and accession no. }\end{array}$ & $\begin{array}{l}\text { Avicennia officinalis } \\
\text { EST GenBank accession no. }\end{array}$ & $e$-value \\
\hline 704864 Signal transduction & Mitochondrial Rho GTPase & 1 & Glycine max GLYMA10G29580.1 & $J Z 721695$ & $9.00 \mathrm{E}-71$ \\
\hline 719405 Signal transduction & Leucine-rich repeat protein kinase & 1 & Arabidopsis thaliana AT5G49760.1 & JZ721696 & 4.00E-80 \\
\hline 719420 Signal transduction & Serine/threonine-protein kinase & 1 & Glycine max GLYMA07G30791.1 & $J Z 721697$ & $3.00 \mathrm{E}-57$ \\
\hline 720115 Signal transduction & $\begin{array}{l}\text { Casein kinase II, alpha chain, } \\
\text { putative }\end{array}$ & 1 & Oryza sativa LOC_Os07g02350.1 & $J Z 721679$ & 4.00E-100 \\
\hline 720108 Signal Transduction & Xylem cysteine peptidase 2 & 1 & Arabidopsis thaliana AT1G20850.1 & JZ721680 & $1.00 \mathrm{E}-26$ \\
\hline 708681 Signal transduction & $\begin{array}{l}\text { Serine/arginine-rich protein } \\
\text { splicing factor } 34 \mathrm{~b}\end{array}$ & 1 & Arabidopsis thaliana AT4G02430.1 & $J Z 721698$ & $8.00 \mathrm{E}-50$ \\
\hline 721424 Metabolism/Amino acid & Trypsin family protein & 1 & Arabidopsis thaliana AT5G45030.1 & $J Z 721699$ & $1.00 \mathrm{E}-95$ \\
\hline 694067 Metabolism/Amino acid & Glutamate synthase & 2 & Oryza sativa LOC_Os01g48960.1 & $J Z 721681$ & 4.00E-107 \\
\hline 708680 Metabolism/Amino acid & Arginine decarboxylase & 1 & $\begin{array}{l}\text { Populus trichocarpa } \\
\text { POPTR_0004s17020.1 }\end{array}$ & $J Z 721700$ & $3.00 \mathrm{E}-81$ \\
\hline 708683 Metabolism/Lipid & ATP-citrate lyase & 1 & Arabidopsis thaliana AT1G60810.1 & $J Z 721701$ & 0 \\
\hline 694059 Metabolism/Lipid & Phospholipase D & 1 & Glycine max GLYMA07G03490.3 & $J Z 721702$ & $3.00 \mathrm{E}-160$ \\
\hline 719630 Metabolism/Lipid & 3-ketoacyl-CoA synthase & 4 & Glycine max GLYMA04G20620.1 & JZ721682 & 4.00E-48 \\
\hline 719448 Metabolism/Protein & $\begin{array}{l}\text { Protein translation factor SUI1 } \\
\text { homolog }\end{array}$ & 1 & Oryza sativa LOC_Os07g34589.2 & JZ721683 & $6.00 \mathrm{E}-83$ \\
\hline 714704 Metabolism/Protein & $\begin{array}{l}\text { Syringolide-induced } \\
\text { protein 19-1-5 }\end{array}$ & 1 & Glycine max GLYMA17G07240.1 & JZ721703 & 4.00E-15 \\
\hline 720030 Metabolism/Protein & Ribosomal protein $\mathrm{S} 6$ & 1 & Arabidopsis thaliana AT4G31700.1 & $J Z 721710$ & $1.00 \mathrm{E}-154$ \\
\hline 719373 Metabolism/Sugar & $\begin{array}{l}\text { Trehalose 6-phosphatase } \\
\text { synthase S6 }\end{array}$ & 1 & Arabidopsis thaliana AT1G68020.1 & JZ721704 & $1.00 \mathrm{E}-50$ \\
\hline 720067 Metabolism/Vitamin & $\begin{array}{l}\text { 1-aminocyclopropane-1- } \\
\text { carboxylate oxidase }\end{array}$ & 1 & $\begin{array}{l}\text { Populus trichocarpa } \\
\text { POPTR_0002s21750.1 }\end{array}$ & $J Z 721705$ & $1.00 \mathrm{E}-151$ \\
\hline 719392 Metabolism/Energy & Cytochrome-c oxidase & 1 & $\begin{array}{l}\text { Arabidopsis thaliana } \\
\text { AT1G80230.1 }\end{array}$ & $J Z 721688$ & $1.00 \mathrm{E}-46$ \\
\hline 703868 Metabolism/Energy & Thioredoxin $\mathrm{H}$ & 7 & Avicennia marina BM497420.1 & $J Z 721687$ & $8.00 \mathrm{E}-143$ \\
\hline 703936 Stress response & Ubiquitin-conjugating enzyme 2 & 1 & $\begin{array}{l}\text { Arabidopsis thaliana } \\
\text { AT2G02760.1 }\end{array}$ & $J Z 721684$ & 4.00E-52 \\
\hline 719444 Stress response & $\begin{array}{l}265 \text { protease regulatory } \\
\text { subunit } 4 \text { homolog }\end{array}$ & 1 & Oryza sativa LOC_Os07g49150.1 & $J Z 721685$ & $2.00 \mathrm{E}-119$ \\
\hline 719392 Stress response & Dehydrin & 9 & Avicennia marina BM172730.1 & $J Z 721686$ & $9.00 \mathrm{E}-42$ \\
\hline 703860 Stress response & Peroxidase & 1 & Avicennia marina BM173160.1 & $J Z 721712$ & $1.00 \mathrm{E}-175$ \\
\hline 724765 Stress response & Disease resistance & 1 & Avicennia marina BM497281.1 & $J Z 721711$ & $1.00 \mathrm{E}-65$ \\
\hline 704843 Transcription factor & $\begin{array}{l}\text { NAC domain containing } \\
\text { protein } 32\end{array}$ & 4 & $\begin{array}{l}\text { Arabidopsis thaliana } \\
\text { AT1G77450.1 }\end{array}$ & $J Z 721689$ & $1.00 \mathrm{E}-24$ \\
\hline 709313 Transcription factor & $\begin{array}{l}\text { Transcription factor R2R3 factor } \\
\text { gene family }\end{array}$ & 3 & $\begin{array}{l}\text { Arabidopsis thaliana } \\
\text { AT3G12720.1 }\end{array}$ & $J Z 721690$ & $2.00 \mathrm{E}-13$ \\
\hline 719394 Transcription factor & Auxin signaling F-box 2 & 1 & $\begin{array}{l}\text { Arabidopsis thaliana } \\
\text { AT3G26810.1 }\end{array}$ & $J Z 721706$ & $7.00 \mathrm{E}-45$ \\
\hline 720062 Transcription factor & Salt-inducible zinc finger 2 & 1 & $\begin{array}{l}\text { Arabidopsis thaliana } \\
\text { AT2G40140.1 }\end{array}$ & $J Z 721691$ & $9.00 \mathrm{E}-41$ \\
\hline 713984 Transcription factor & Transcription factor HBP-1b & 1 & Oryza sativa LOC_Os01g59350.1 & $J Z 721707$ & $2.00 \mathrm{E}-22$ \\
\hline 714010 Transcription factor & $\begin{array}{l}\text { AP2 domain-containing } \\
\text { transcription factor }\end{array}$ & 1 & $\begin{array}{l}\text { Populus trichocarpa } \\
\text { POPTR_0016s08530.1 }\end{array}$ & $J Z 721708$ & $3.00 \mathrm{E}-73$ \\
\hline 694065 Transporter/ABC & $\begin{array}{l}\text { White-brown-complex ABC } \\
\text { transporter family }\end{array}$ & 4 & $\begin{array}{l}\text { Arabidopsis thaliana } \\
\text { AT1G51460.1 }\end{array}$ & $J Z 721692$ & $5.00 \mathrm{E}-23$ \\
\hline
\end{tabular}


Table 1 Avicennia officinalis ESTs identified from salt gland-rich tissue after subtractive hybridization (Continued)

\begin{tabular}{llrlll}
\hline 720073 Transporter/lon & Vacuolar ATP synthase subunit D & 1 & $\begin{array}{l}\text { Arabidopsis thaliana } \\
\text { AT3G58730.1 }\end{array}$ & JZ721693 & 2.00E-108 \\
709299 Transporter/lon & Plasma membrane H+ATPase & 1 & Avicennia marina BM172881.1 & JZ721694 & 6.00 E-179 \\
719615 Transporter/Water & Aquaporin & 3 & Oryza sativa LOC_Os04g47220.1 & JZ721709 & 7.00 E-119
\end{tabular}

Functional annotation was done after blasting the sequences with various plant gene databases. Clone ID with classification (column 1) and the putative function (column 2) based on comparison with reference organisms are shown. Occurrence frequency $\left(\mathrm{O}_{\mathrm{f}}\right.$ ), which is the number of times a specific EST was identified in the SH is given in column 3. The reference organism to which the EST was compared with and its accession number are given in columns 4 and Avicennia officinalis EST GenBank accession numbers are given in column 5 . The e-values of sequence comparison of the A. officinalis ESTs with the reference sequences are given in column 6.

\section{cDNA and genomic DNA sequences of AoDHN1}

Subtractive hybridization of $A$. officinalis led to the identification of an EST (AoDHN1) that showed homology to Avicennia marina Dehydrin1 (AmDHN1). The coding sequence of $A o D H N 1$ is $573 \mathrm{bp}$ and the corresponding genomic sequence is $679 \mathrm{bp}$, because of the presence of an intron (106 bp) (Figure 3A). The cDNA sequence stretch coding for a single uninterrupted polypeptide of 190 amino acids was identified by in silico translation of the sequence corresponding to AoDHN1, with a deduced molecular mass of $19.82 \mathrm{kDa}$. A nuclear localization sequence (NLS) RRKK has been identified towards the C-terminus of AoDHN1 suggesting that it could be a nuclear-localized protien (Figure 3C). Also, the location of the intron has been identified in the genomic DNA sequence (Figure 3C). The predicted two-dimensional structure of the dehydrin proteins using PSIPRED revealed a major unstructured region and two possible $\alpha$-helices (see Additional file 2). Additionally, the threedimensional structure of AoDHN1 generated using iTASSER confirmed the presence of the unstructured region along with two $\alpha$-helices (Figure 3D).

\section{Classification of AoDHN1 as a Group II LEA protein}

Sequence alignment with group II LEA proteins of other plant species showed that AoDHN1 belongs to YSK2 sub-class of dehydrins (Figure 4A). The amino acids from 12 to 18 (TDEYGNP) correspond to the Y segment, while amino acids from 107 to 124 correspond to the S segment, and there are two K segments stretching from amino acids 129 to 141 and 173 to 187 . Because this dehydrin possesses one $\mathrm{Y}$, one $\mathrm{S}$ and two $\mathrm{K}$ segments, it is named as the YSK2 sub-group (Figure 4A and 4B). Only the domain-specific regions (YSK2) show consensus between AoDHN1 and other dehydrins (group II LEA proteins). AoDHN1 shows a high similarity index of $84 \%$ with AmDHN1 and both the dehydrins were found to be closely related based on phylogenetic analysis (Figure 4C).

\section{AoDHN1 copy number in the genome}

A full length gene probe showed two copies of Dehydrin in a genomic Southern blot analysis (Figure 5A). On examining the sequence similarity with Dehydrin sequences obtained in our lab from A. officinalis transcriptome analysis (unpublished data), it was found that another Dehydrin (AoDHN2) sequence shared high similarity with $A o D H N 1$ (Figure $5 \mathrm{~B}$ ). This confirmed the identification of two Dehydrins in the genome of A. officinalis.

\section{Characterization of AoDHN1}

Tissues collected from two-month-old seedlings that were not exposed to salt were used for tissue-specific expression analysis. The highest expression of AoDHN1 was observed in the leaves compared to roots (root apical, root mid and root basal) and stems (Figure 6A). In situ hybridization studies from leaves of two-month-old $A$. officinalis seedlings confirmed abundant expression of AoDHN1 in salt glands (Figure inset of 6A). Expression kinetics of $A o D H N 1$ was tested in both roots and leaves of A. officinalis seedlings upon salt treatment (Figure 6B and 6C). A 10-fold increase in expression levels of $A o D H N 1$ in the roots was seen after $8 \mathrm{~h}$ while a 2 -fold increase was seen in the leaves after $48 \mathrm{~h}$ of salt treatment.

Leaf discs from two-month-old seedlings (previously not exposed to salt) were chosen to study the regulation of AoDHN1 by abiotic stresses (Figure 6D). Drought treatment for $1 \mathrm{~h}$ and $2 \mathrm{~h}$ showed a 2- and 6-fold increase respectively, in the expression of $A o D H N 1$. However, abscisic acid (ABA) and salt treatments did not affect the expression of AoDHN1 up to $2 \mathrm{~h}$.

Transient expression of 35S::AoDHN1-GFP construct transfected into Arabidopsis mesophyll protoplasts showed the localization of AoDHN1-GFP fusion protein in the cytosol as well as the nucleus (Figure 7). Yellow fluorescence from YFP fused with the nuclear localization signal of SV40 was used to detect the nucleus.

\section{Functional assay of AoDHN1 in E. coli cells}

Salinity $(\mathrm{NaCl})$ and drought (mannitol and polyethylene glycol 4000 - PEG) stress response of AoDHN1 in E. coli bacteria was tested. The E. coli (BL21 cells) transfected with $p G E X-6 p-1-A o D H N 1$ and empty vector separately, were subjected to $400 \mathrm{mM} \mathrm{NaCl}, 500 \mathrm{mM}$ mannitol and $10 \%$ PEG treatment. A control study was done without any treatment to check the difference in growth between $E$. coli cells transfected with $p G E X-6 p-1-A o D H N 1$ and empty vector. $\mathrm{OD}_{600}$ of the bacterial culture was taken at $2 \mathrm{~h}$ time intervals after induction of AoDHN1 expression 
A

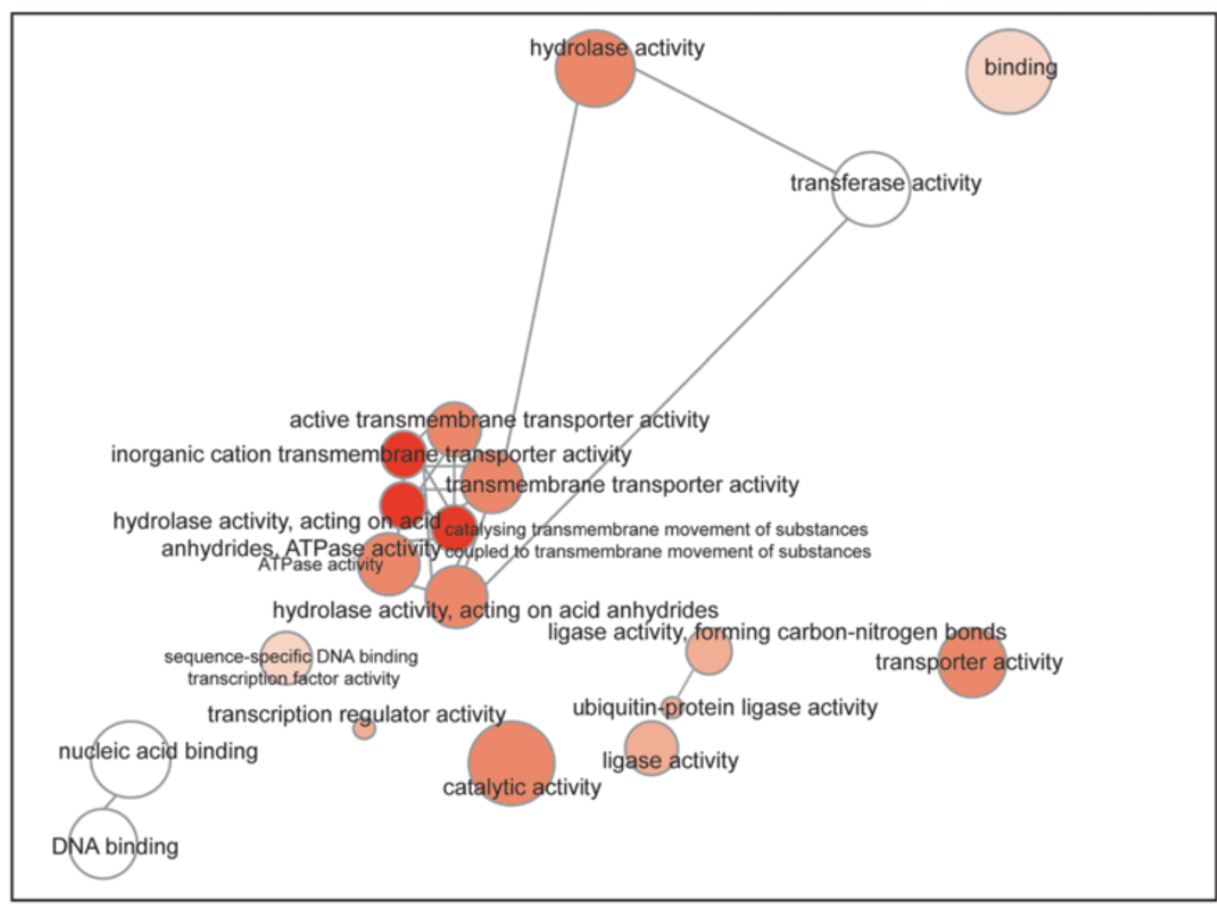

B

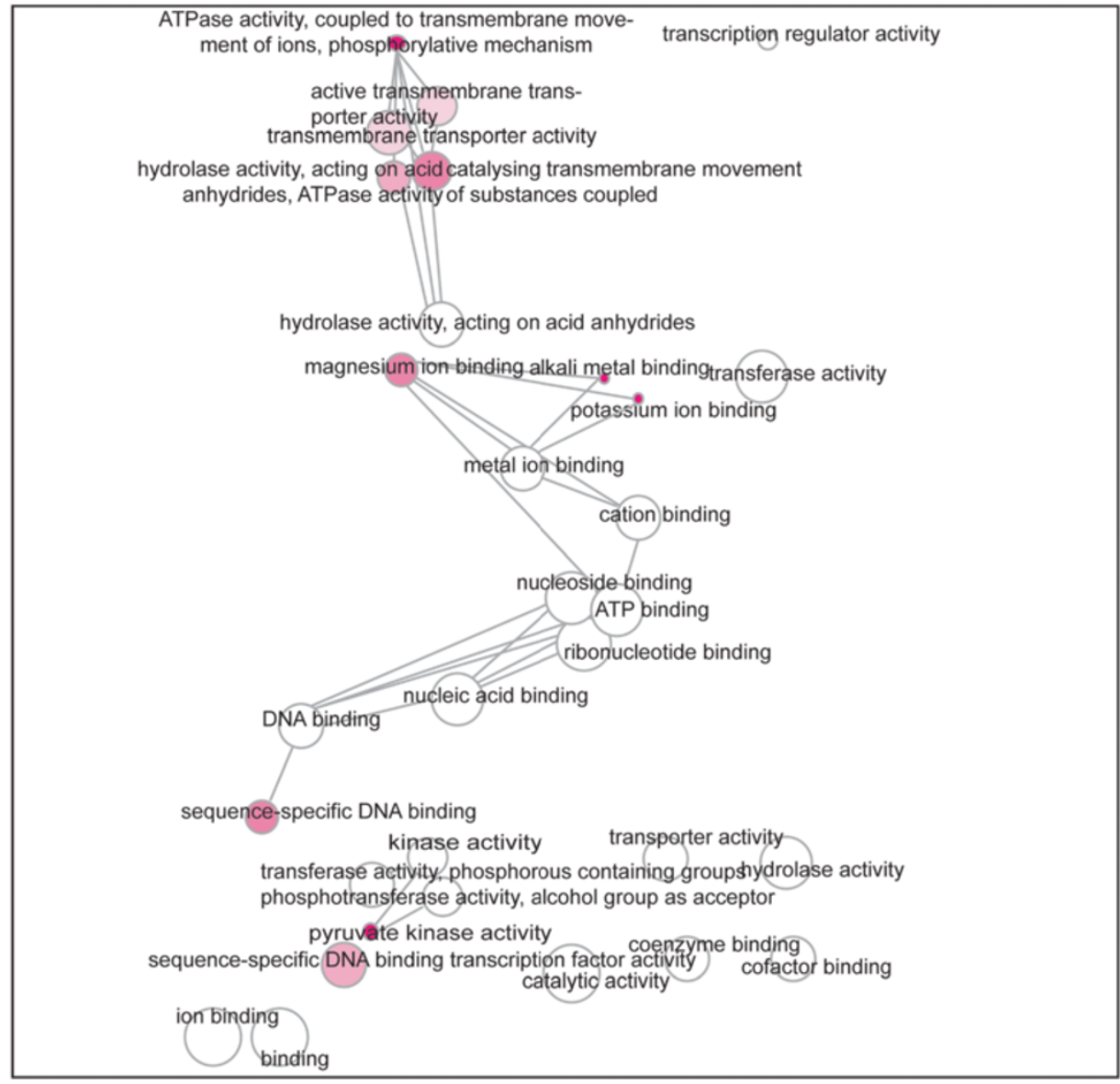

Figure $\mathbf{2}$ (See legend on next page.) 
(See figure on previous page.)

Figure 2 Functional gene-network analysis of the ESTs identified from subtractive hybridization. Interactive graph was generated using web-tool REVIGO (http://revigo.irb.hr/) as on $9^{\text {th }}$ December 2013. The bubble colour indicates the p-value as generated by Singular Enrichment Analysis of the Gene Ontology (GO) terms obtained from the web-tool agriGO (http://bioinfo.cau.edu.cn/agriGO/analysis.php). The gene IDs that resulted by blasting the ESTs against (A) Arabidopsis and (B) Poplar CDNA libraries were used to generate the GO terms. Bubble size indicates the frequency of the GO term. Highly similar GO terms are linked by edges in the graph, where the line width indicates the degree of similarity.

by IPTG-treatment. The E. coli cells expressing AoDHN1 showed better growth (as represented by higher cell density) compared to the control after $6 \mathrm{~h}$ (Figure 8A) even in the absence of any treatment. With $\mathrm{NaCl}$ treatment, the cell densities started to show significant differences from $8 \mathrm{~h}$ onwards (Figure 8B). Upon mannitol treatment, E. coli cells expressing AoDHN1 showed significantly higher growth between $8 \mathrm{~h}$ and $10 \mathrm{~h}$ (Figure $8 \mathrm{C}$ ). On the other hand, with PEG treatment, the difference in growth was apparent from $6 \mathrm{~h}$ and lasted up to $9 \mathrm{~h}$ (Figure 8D). Therefore, the protective function of AoDHN1 protein was demonstrated by the growth advantage conferred under salinity and drought stresses for $E$. coli cells expressing AoDHN1.

\section{Discussion}

Salt secretion is a dynamic and energy dependent process as shown in Avicennia species [9,39]. Identification of genes that are expressed in salt glands will help in understanding the secretion process. While many genes related to salt tolerance have been identified using $\mathrm{SH}$ and transcriptome analysis from the leaves of other mangrove

A

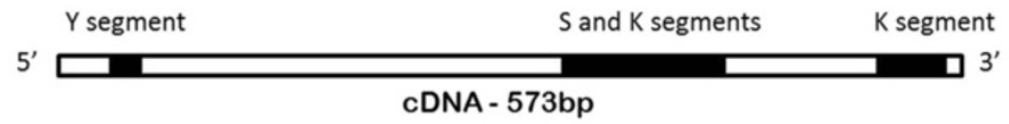

B

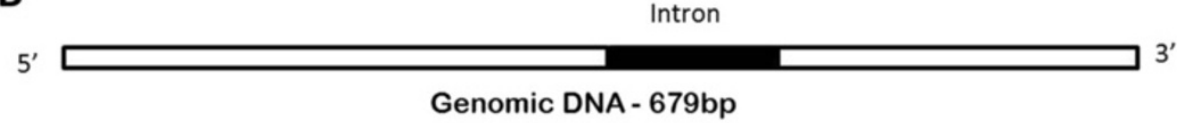

C

1 atgtcagagtacggcgaccaatacgggcgacagaccgacgagtac $\begin{array}{lllllllllllllllllllll}M & S & E & Y & G & D & Q & Y & G & R & Q & T & D & E & Y\end{array}$

46 ggcaatcccatccgccagactggcgagtatggagctaccggaact $\begin{array}{llllllllllllllllll}G & N & P & I & R & Q & T & G & E & Y & G & A & T & G & T\end{array}$

91 tacgggactaatcagcagtatggaaccaccgacaccactggagcg $\begin{array}{lllllllllllllll}Y & G & T & N & Q & Q & Y & G & T & T & D & T & T & G & A\end{array}$

136 tataagactgatccgcacggcaccaccggggcctataagactgat $\begin{array}{lllllllllllllll}Y & K & T & D & P & H & G & T & T & G & A & Y & K & T & D\end{array}$

181 caatatggaaccaccggagcatacgggactgatcggtacggaact $\begin{array}{llllllllllllllll}Q & Y & G & T & T & G & A & Y & G & T & D & R & Y & G & T\end{array}$

226 acggacaccaccggggcatatgggactcacggtggtgggattgct $\begin{array}{lllllllllllllll}T & D & T & T & G & A & Y & G & T & H & G & G & G & I & A\end{array}$

271 cctggagcaactgatgctggcetggatggcggcggccgcggccac $\begin{array}{lllllllllllllllll}P & G & A & T & D & A & G & L & D & G & G & G & R & G & H & \text {. Intron }\end{array}$ 316 caccgtcgctctggcagctcaagcagctcottcttcggaggacgat location

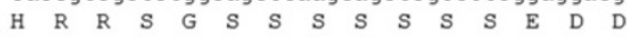

361 gggcaaggtgggaggagaaagaaggggataaaggagaagataaag $G$ G G R R K K G I K E K I K NLS sequence 406 gaaaaactgccgggcggcggtcacggggatgatcagactcacccc

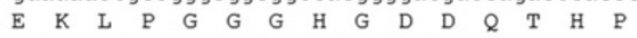

451 actccagctggcggtggtggatatggttatgaacacggaggagcc $\begin{array}{llllllllllllllll}T & P & A & G & G & G & G & Y & G & Y & E & H & G & G & A\end{array}$

496 gccgacggcccagagcacgaagagaagaagggaataatggagaag $\begin{array}{llllllllllllllllllllllllll}A & D & G & P & E & H & E & E & K & K & G & I & M & E & K\end{array}$ 541 ataaaggaaaagctgccoggaggccaccattaa 573 $\begin{array}{llllllllllllllll}I & K & E & K & L & P & G & G & H & H & *\end{array}$

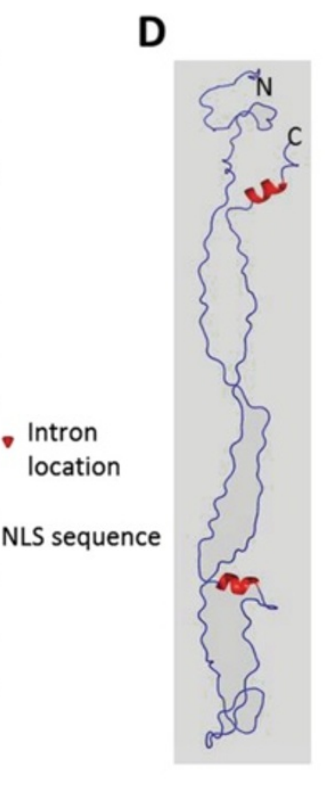

Figure 3 cDNA and genomic DNA sequences of AoDHN1. (A) CDNA of 573 bp corresponding to Open Reading Frame (ORF) of AoDHN1 obtained from Rapid Amplification of cDNA Ends (RACE) PCR. Y, S and two of K segments are depicted on the ORF. (B) Genomic fragment of AoDHN1 with intron of $107 \mathrm{bp}$. (C) Nucleotide sequence of AoDHN1 and its corresponding translated protein sequence. Arrowhead indicates intron location and underline indicates Nuclear Localization Signal (NLS) sequence. (D) Predicted three dimensional structure of AoDHN1 obtained using iTASSER server (http://zhanglab.ccmb.med.umich.edu/I-TASSER/) showing two alpha helices (in red), but the rest of the molecule is unstructured. 


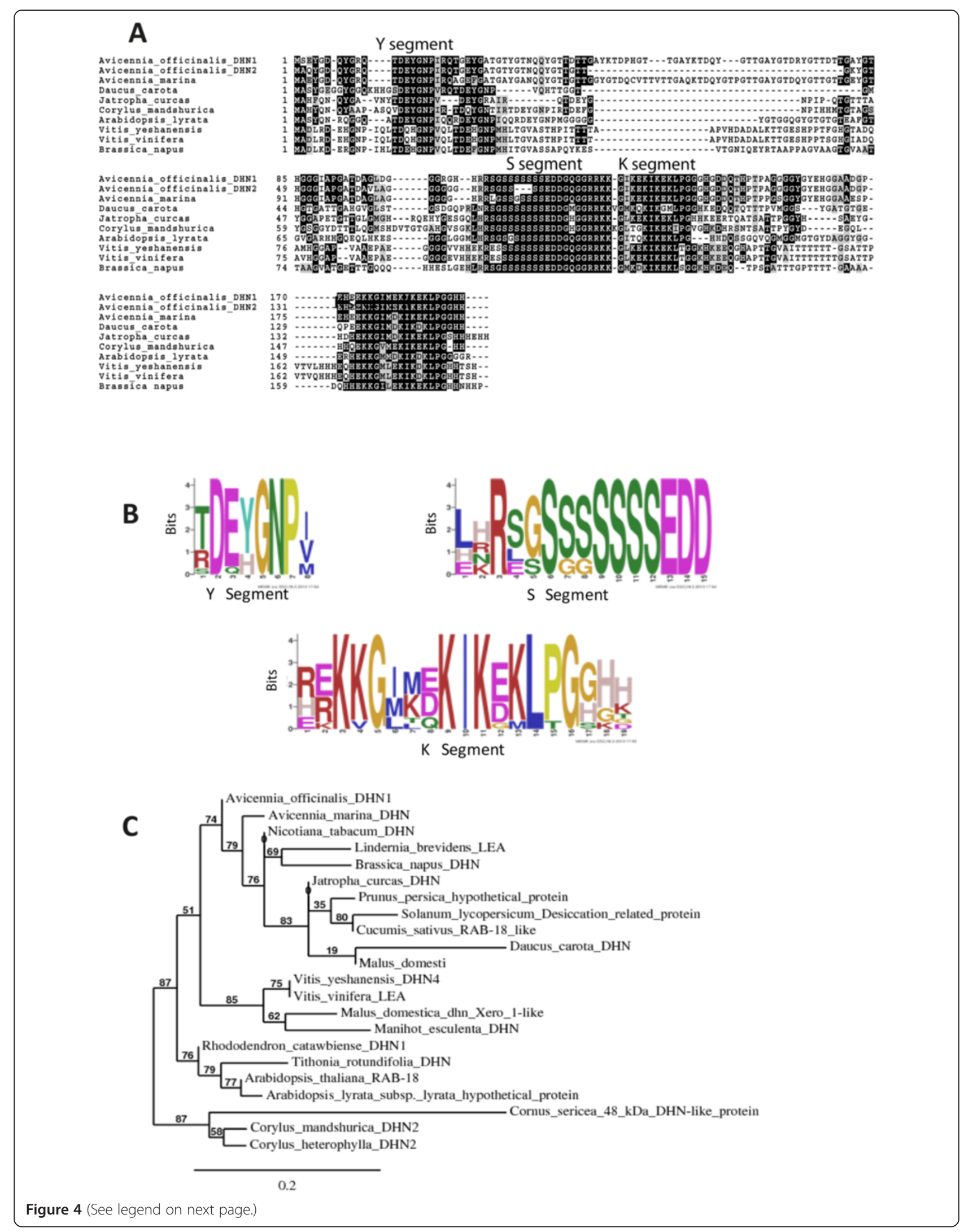


(See figure on previous page.)

Figure 4 Classification of AoDHN1 into Group II LEA protein based on sequence alignment and phylogenetic analysis. (A) Alignment of AoDHN1 and AoDHN2 protein sequences with dehydrins from other plant species. The shaded region shows the conserved motif YSK2 (http:// www.ch.embnet.org/software/BOX_form.html). (B) Conserved sequence motifs identified from AoDHN1 using MEME web-tool (http://meme.nbcr. net/meme/). Amino acid pattern that occurs repeatedly in YSK2 family dehydrins are represented in position-dependent manner. (C) The phylogenetic relationship of AoDHN1 with group II LEA proteins of different species is represented in rooted dendrogram. It was constructed using Phylogeny.fr web-tool (http://phylogeny.lirmm.fr/phylo_cgi/simple_phylogeny.cgi) by the approximate likelihood method based on a complete protein sequence alignment of different dehydrins and the approximate likelihood-ratio test. The branch support values are shown at the nodes as percentage values and scale bar indicates the branch lengths. The gi numbers for the sequences are: $|g b| \mathrm{KM} 652423 \mid$ AoDHN1 [Avicennia officinalis]; gi|157497151|gb|ABV58322.1| dehydrin [Avicennia marina]; gi|349844874|gb|AEQ19906.1| dehydrin 4 [Vitis yeshanensis]; gi|225428392| ref|XP_002283605.1] PREDICTED: late embryogenesis abundant protein-like [Vitis vinifera]; gi|353685443|gb|AER13140.1] DHN2 [Corylus mandshurica]; gil 307776652|gb|ADN93460.1| dehydrin 2 [Corylus heterophylla]; gi|314998614|gb|ADT65201.1| dehydrin [Jatropha curcas]; gi|449457626|ref|XP_004146549.11 PREDICTED: dehydrin Rab18-like [Cucumis sativus]; gi|442022395|gb|AGC51773.1| dehydrin protein [Manihot esculenta]; gi|34539778|gb|AAQ74768.1| dehydrin [Brassica napus]; gi|657980608|ref|XP_008382297.1| PREDICTED: late embryogenesis abundant protein [Malus domestica]; gi|57506540|dbj|BAD86644.11 dehydrin protein [Daucus carota]; gi|15239373|reffNP_201441.1| dehydrin Rab18 [Arabidopsis thaliana]; gi|472278804|gb|AG/37442.1| dehydrin 1 [Rhododendron catawbiense]; gi|18076154|emb|CAC80717.1| putative dehydrin [Tithonia rotundifolia]; gi|595807384|ref|XP_007202596.1| hypothetical protein PRUPE_ ppa011637mg [Prunus persica]; gi|297794373|ref|XP_002865071.1| hypothetical protein ARALYDRAFT_496967 [Arabidopsis lyrata subsp. Iyrata]; gi|19032422|gb| AAL83427.1|AF345989_1 48 kDa dehydrin-like protein [Cornus sericea]; gi|657948498|ref|XP_008338082.1| PREDICTED: dehydrin Xero 1-like [Malus domestica]; gil 129562715|gb|ABO31098.1| late embryogenesis abundant protein [Lindernia brevidens]; gi|46020012|dbj|BAD13498.1] dehydrin [Nicotiana tabacum]; gi| 460373256|ref|XP_004232437.1| PREDICTED: desiccation-related protein clone PCC6-19-like isoform 2 [Solanum lycopersicum].

species [22-24,40-43], there have been no attempts to specifically identify the genes that are expressed in salt glands.

A meaningful way of analysing $\mathrm{SH}$ data obtained from our experiment was to create a network using REVIGO, of the ESTs of $A$. officinalis against Arabidopsis and poplar cDNA libraries which would give an overview of functional gene interaction in salt gland-rich tissue [38]. This collection of ESTs from salt gland-rich tissue depicts potential interaction between gene products either with each other or with other molecules in the cell, thereby suggesting the global functional network. The interactive Gene Ontology (GO) map of the ESTs with both Arabidopsis and poplar cDNA libraries suggests that activities of hydrolase, transmembrane transport, nucleotide binding and kinase functions are common in the selected tissue (Figure 2A and 2B). Transmembrane transport includes channels, pumps and transporters, which are

A

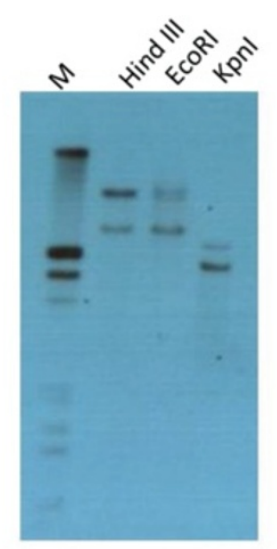

B

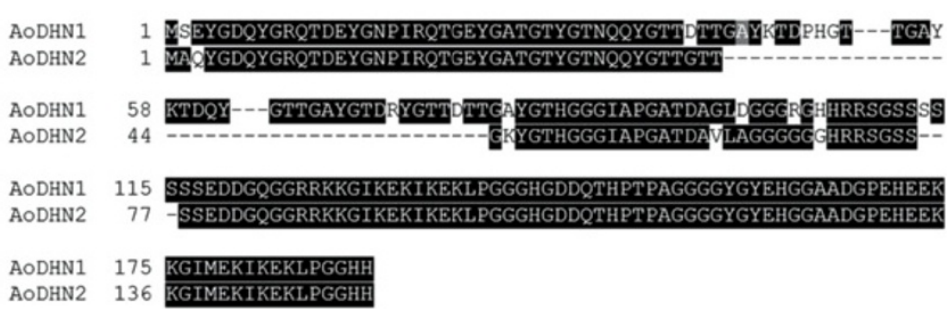

Figure 5 AoDHN1 copy number in the genome. (A) Genomic Southern blot showing two copies of AoDHN1 in Avicennia officinalis. (B) Alignment of AoDHN1 and AoDHN2 (dehydrin obtained from transcriptome sequencing) using ClustalW2 multiple alignment (http://www.ebi.ac. uk/Tools/msa/clustalw2/) and represented using the web-tool BoxShade Server (http://www.ch.embnet.org/software/BOX_form.html). 


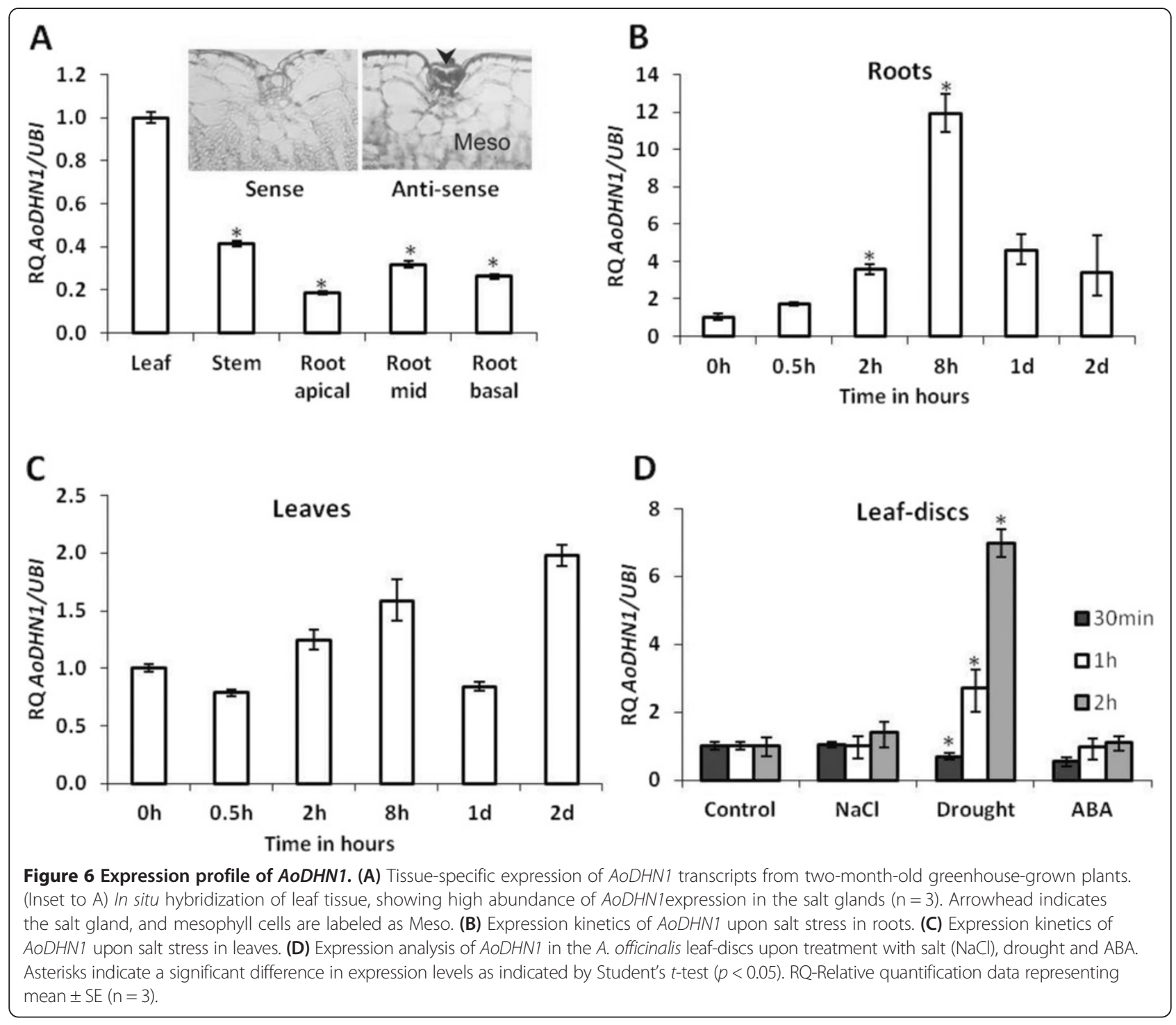

important in maintaining ion homeostasis and contribute to salt tolerance. Ion transporters like $\mathrm{H}^{+}$-ATPases, V-ATPases and SOS1(Salt Overly Sensitive1) are known to bring about ionic balance in the cell [26], while transporters like aquaporins stabilize water movement and contribute to osmotic regulation [9]. Kinases identified from our study belong to Receptor-Like Kinases (RLKs) which regulate several plant processes such as growth, development and homeostatic mechanisms intrinsic to abiotic stress response [44]. This visual outline aids in understanding the possible functional relations of the identified ESTs from salt gland-rich tissue of $A$. officinalis.

\section{Identification of genes that are highly expressed in salt gland-rich tissue}

Aquaporins and $\mathrm{ABC}$ transporters were the major transporters identified in our study. $A B C$ transporters are known to transport fatty acids that are required for proper cuticle development in leaves [45]. The cuticle plays an important role in maintaining the structural integrity of salt glands. Under saline conditions, it becomes important for the salt glands to form a thick cuticular layer to prevent water loss and also diffusion of ions into neighbouring cells [6]. The observed high level of expression of $\mathrm{ABC}$ transporters in the salt gland-rich tissue could explain this in Avicennia salt gland cells. Aquaporins are known to regulate water movement across the membranes. During drought and salt exposure, aquaporins are known to maintain water balance in the cells [46] and have been shown to play a crucial role in salt secretion of $A$. officinalis [9]. Although aquaporins have been identified from the leaves of other salt secretors [41], its precise function in regulating water movement during secretion is not clear. Another major class of ESTs identified was related to metabolic processes. Physiological response of the plant is known to 


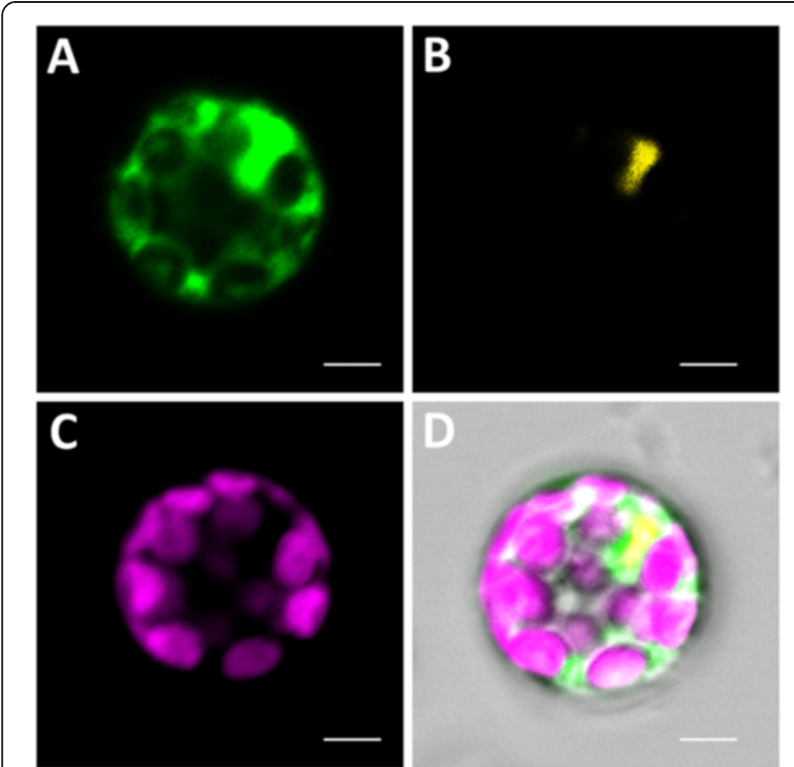

Figure 7 Sub-cellular localization of GFP fused AoDHN1 in Arabidopsis mesophyll protoplasts. (A) Localization of AoDHN1-GFP in the cytoplasm and nucleus (B) Position of the nucleus is indicated by yellow fluorescence from YFP fused with nuclear localization signal of

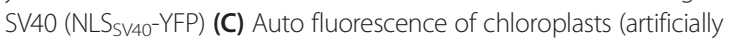
coloured purple) (D) Merged image of (A) (B) (C) and (D) overlaid on transmitted light image of the protoplast. Scale bar $=5 \mu \mathrm{m}$. be altered due to metabolic changes under salt stress. Abiotic stresses usually cause energy deprivation, therefore plants tend to regulate metabolic genes by suppressing genes encoding biosynthetic enzymes of amino acids to conserve energy, and induce genes coding catabolic enzymes of amino acids to provide energy [47]. Cysteine peptidase identified from our SH study is known to play a role in plant stress response by participating catabolic process [48]. Ethylene plays an important role during salt stress [49] and ethylene biosynthesis is regulated by the levels of ACC oxidase activity [50], which is reported to have a positive effect on salinity tolerance [51]. The roles played by these genes in salt secretion and tolerance are still not clear, but the complexity of the underlying metabolic processes is highlighted. Our observations provide further evidence to the view that a combined action of different metabolic pathways and active expression of various transporters would have to be occurring in order to maintain cellular homeostasis under stress.

Among the class of stress-related proteins, a dehydrin was identified. Dehydrins are hydrophilic and highly flexible proteins (Intrinsically Unstructured Proteins, IUPs) that protect cytosolic and membrane proteins by wrapping around them [52] ('molecular-huggers'). They seem to function similar to chaperones by stabilizing the protein folding, but dehydrins are much smaller in size and are less complex compared to chaperones. Because they
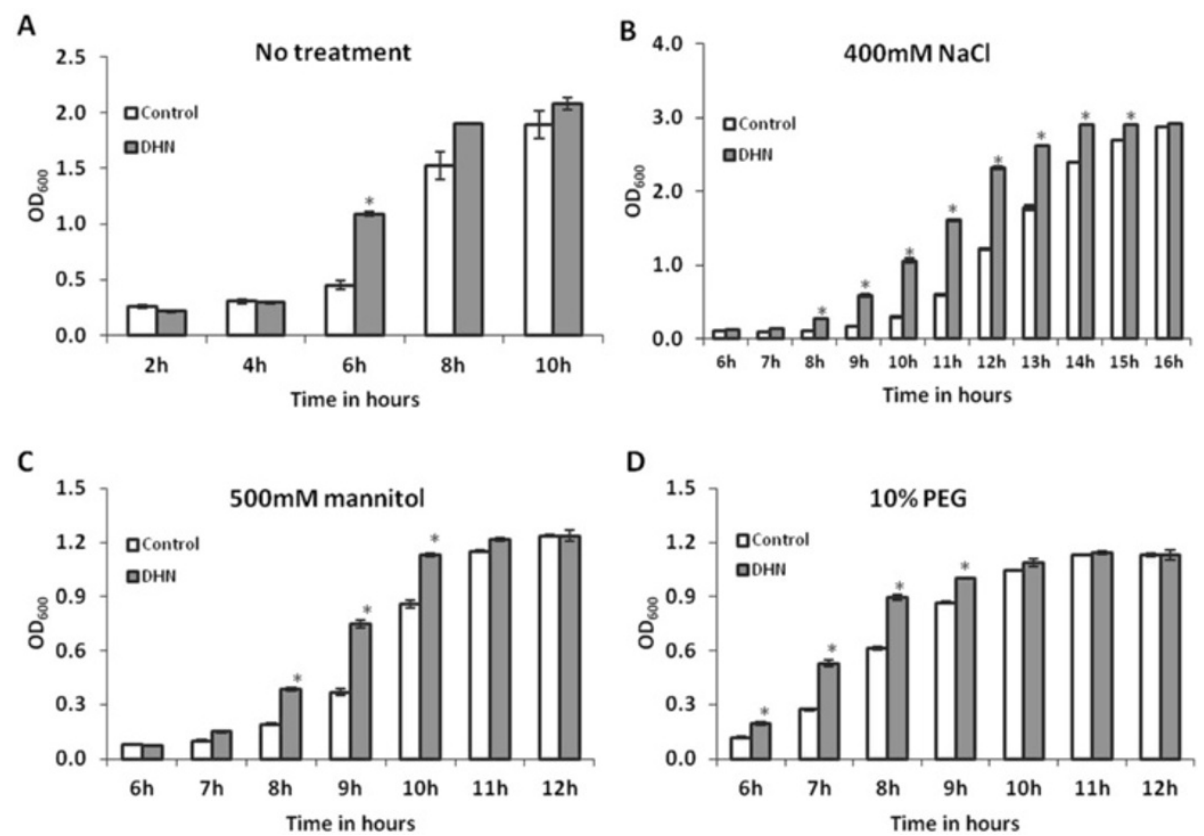

Figure 8 Comparison of growth of $E$. coli cells expressing AoDHN1 under salt and drought stress conditions. Salt stress was simulated by $400 \mathrm{mM} \mathrm{NaCl}$, and drought conditions were provided by $500 \mathrm{mM}$ mannitol and 10\% polyethylene glycol (PEG). E. coli BL21 cells expressing AoDHN1 showed significant differences in cell densities compared to control cells which do not express AoDHN1 over specified periods of time. (A) without any treatment (B) with $400 \mathrm{mM} \mathrm{NaCl}$ treatment (C) with $500 \mathrm{mM}$ mannitol treatment and (D) with 10\% PEG 4000 treatment. Data are mean \pm SE $(n=3)$. Asterisks indicate a significant difference in cell densities as indicated by Student's $t$-test $(p<0.05)$. OD - Optical Density. 
belong to IUPs, it has been quite challenging to determine their precise function through structural studies. However, due to their significant association with protecting proteins against physiological drought, dehydrin was chosen for further examination in our study.

Dehydrins have been identified in a wide variety of organisms such as bacteria, chironomid, brine shrimp, nematodes, rotifers and cyanobacteria in response to desiccation [53], and are well-studied in plants for their key role in response to abiotic stress. Like group I LEA proteins, several studies of specific group II LEA proteins have confirmed that they accumulate during seed desiccation and in response to water deficit induced by drought, low temperature, or salinity $[54,55]$.

A characteristic feature of group II LEA proteins is the presence of conserved domains such as $\mathrm{Y}, \mathrm{S}$ and $\mathrm{K}$. The K-segment consists of Lys-rich 15-residue motif, EKKGIMDKIKEKLPG [32], the Y-segment consensus sequence is $[\mathrm{V} / \mathrm{T}] \mathrm{D}[\mathrm{E} / \mathrm{Q}] \mathrm{YGNP}[31,56]$ and serine rich S-segment contains LHRSGS4-10(E/D)3, which in some proteins can be phosphorylated [57]. The ORF encoded by $A o D H N 1$ has a single ' $\mathrm{Y}$ ' segment, characterized by the presence of amino acids 'DEYGNP' followed by a serine-rich tract and two lysine-rich ' $K$ ' segments (Figure 4), and hence it belongs to the YSK2 class of dehydrins [58]. This is the most abundant class of dehydrins and is known to be induced by ABA and drought, but not cold temperatures [58]. AmDHN1 is the only other mangrove dehydrin studied that belongs to YSK2 class of proteins [37] while a K-type dehydrin has been identified in Rhizophora mucronata [59]. However, our study is the first one to report that AoDHN1 is preferentially expressed in the salt gland cells.

\section{Expression and regulation of AoDHN1}

Dehydrins are present in most of the vegetative tissues under optimal growth conditions [33]. Dehydrins from Arabidopsis, Craterostigma and Citrus have been shown to prevent inactivation of enzymes induced by partial dehydration in vitro $[36,60]$. Although some of the previous reports showed that dehydrins are expressed in all parts of the plants, the present study provides evidence for the preferential expression of AoDHN1 in A. officinalis salt glands (Figure 1B, 6A and inset of 6A). Studies from several plant species indicated that different types of group II LEA proteins are present in various tissue types $[55,61]$, which explains the preferential expression of AoDHN1 observed in our study. Moreover, the unstructured nature of dehydrins was suggested to allow them to maintain enough water molecules in the cellular microenvironment and thus stabilize the macromolecules during water scarcity [36]. Since salt glands are the main site of secretion, there will be high concentration of ions in the cells, and hence it is conceivable that the macromolecules within those cells might require the protective action provided by dehydrins. It is therefore not a coincidence to find high level of AoDHN1 expression in the salt glands as observed in our study. Further studies are needed to understand the exact mechanism by which this protective function is conferred within the salt gland cells.

Dehydrins are known to accumulate in every tissue upon water deficit imposed by abiotic stresses, such as drought and salinity [33]. A group II LEA gene from rice (Oryza sativa) was found to be specifically ABA-responsive and not directly responsive to salt stress [62]. While in sunflower, elevated dehydrin transcript levels appeared independent of ABA content in late embryogenesis [61] and paf 93 which belongs to dehydrin family from barely did not respond to exogenous ABA treatments [60]. Hence, we decided to examine if $A o D H N 1$ has specificity in its response to salinity, drought and ABA in A. officinalis leaf discs subjected to these stresses. The observed activation of $A o D H N 1$ in response to drought (Figure 6D) and salt (Figure 6B and 6C), but not ABA treatment (Figure 6D) suggests AoDHN1 responds to the abiotic stresses independently of ABA. These observations are in agreement with some of the earlier reports [63,64].

A majority of group II LEA proteins accumulate in the cytoplasm while some of them have been shown to localize in the nucleus as well [65]. Our data showed that GFP-fused AoDHN1 was transiently expressed in Arabidopsis mesophyll protoplasts, the protein was present in both the cytosol and nucleus, which is similar to the observation with AmDHN1 from A. marina [37] and Rab17/ DHN1 from maize [57]. This suggests that AoDHN1 may function as non-specific protectant by binding to proteins in the cells under stress.

We demonstrated the protective role of AoDHN1 in $E$. coli cells expressing the protein and subjected to salinity and drought stress conditions. The significant increase in cell density at $6 \mathrm{~h}$ without any treatment compared to control cells without AoDHN1 (Figure 8A) suggests the overall growth advantage provided by the protein. Thus, our data suggest that AoDHN1 may help in stabilizing the cells during abiotic stress conditions even in A. officinalis.

\section{Conclusions}

In conclusion, we have identified several novel genes that are specifically expressed in the salt gland-rich tissues of A. officinalis. A gene interactive network has been generated based on the ESTs identified from SH analysis. A dehydrin gene $A o D H N 1$ that is highly expressed in salt gland cells was identified and cloned. AoDHN1 was upregulated in response to drought and salt treatments and was shown to play an important role in alleviating salt and drought stresses. A. officinalis, which is an obligate halophyte, may use this dehydrin protein to protect the 
cellular components such as enzymes and other macromolecules from dehydration damage caused by physiological drought. The results from our study have helped to identify a key protective protein that represents one of the numerous players in the complex molecular mechanism underlying salt tolerance in mangroves.

\section{Methods}

\section{Plant materials and growth conditions}

Avicennia officinalis stem cuttings from field grown trees and propagules were collected from mangrove swamps near the Berlayer Creek, Singapore $\left(1.27^{\circ} \mathrm{N} ; 103.80^{\circ} \mathrm{E}\right)$ and Sungei Buloh Wetland Reserve, Singapore $\left(1.43^{\circ} \mathrm{N}\right.$; $103.717^{\circ} \mathrm{E}$ ). Propagules were grown in potting mix (Far East Flora, Singapore) in green house condition $\left(25-35^{\circ} \mathrm{C}\right.$, $60-90 \%$ relative humidity; $12 \mathrm{~h}$ photoperiod) watered every alternate day with $\mathrm{NaCl}$-free water.

\section{Tissue preparation and subtractive hybridization}

A. officinalis leaves collected from several field-grown trees were used for $\mathrm{SH}$. The upper epidermal peels were separated from the mesophyll as described earlier [25] and kept frozen separately in $-80^{\circ} \mathrm{C}$ until RNA was extracted. Total RNA was isolated using Qiagen plant RNAeasy kit, from the upper epidermal peels and mesophyll cells. SH was performed using the upper epidermal peel RNA (rich in salt glands) as the tester and mesophyll tissue RNA as the driver. SH service was obtained from First BASE Laboratories (www.base-asia.com).

\section{Data cleaning and gene annotation}

The ESTs of the raw mangrove data were cleaned up to remove the duplicate sequences using the program LAST (http://last.cbrc.jp/). The aligned sequences having $99 \%$ identity were created using the parameter 'lastal -r1 -q99 -a0 -b99 -e150'. The duplicate sequences were then removed based on $100 \%$ identity.

Putative functions were assigned for the unique genes by blasting the unique ESTs against all genes including experimentally verified, predicted and hypothetical genes of the following plant species : Arabidopsis thaliana and Oryza sativa, Glycine max, and Populus trichocarpa by NCBI- BLASTX Algorithim [66]. For this purpose, the cDNA sequences of these plant species were downloaded from Plant GDB database (http://www.plantgdb. org/). Since the cDNA sequences were not available for Avicennia marina, the EST sequences were used to find out the gene similarity. Blast results having more than $70 \%$ identity with an $e$-value cut off of $1 \mathrm{e}^{-10}$ and blast scores more than 50 bits were considered as significant.

\section{Cloning AoDHN1 cDNA and genomic DNA fragment} Full length CDS of AoDHN1 was obtained using SMART RACE cDNA Amplification Kit (Clontech). Sequences were amplified using the primers $5^{\prime}$ - GTCTTCGGAGGA CGATGG 3' (forward) for 3' RACE and 5'-CCATCGTC CTCCGAAGAC-3' (reverse) for 5'RACE. Corresponding genomic DNA sequence was obtained by amplifying the genomic DNA with 5'-ATGTCAGAGTACGGCGA-3 (forward) and 5'-ATGGTGGCCTCCGGGCA-3' (reverse) primers. The fragments generated by RACE and genomic DNA amplification were cloned into pGEMT-Easy vector (Promega) and sequenced.

\section{Sequence comparison and structure prediction of DHNs}

Nucleotide sequences were translated to protein using ExPASy translate (http://web.expasy.org/translate/) The sequence alignment was done using ClustalW2 multiple alignment (http://www.ebi.ac.uk/Tools/msa/clustalw2/) and representation was done using BoxShade Server (http:// www.ch.embnet.org/software/BOX_form.html) which highlight identities and similarities in protein sequence. Secondary structure of the proteins was predicted using PSIPRED (http://bioinf.cs.ucl.ac.uk/psipred/). Three dimensional structure of the protein was predicted using iTASSER (http://zhanglab.ccmb.med.umich.edu/I-TASSER/).

\section{Treatment protocols}

For tissue-specific expression, leaf, stem and root tissues from two-month-old $A$. officinalis plants were used. Plants that were transferred to pots containing sand and allowed to adapt for two days by watering with half-strength Hoagland's solution were used for this purpose. These plants were later subjected to $500 \mathrm{mM} \mathrm{NaCl}$ treatment (also in half-strength Hoagland's solution) to study the expression kinetics of $A o D H N 1$ in roots and leaves.

To study the expression pattern of $A o D H N 1$ during abiotic stress, leaf-discs from two-month-old $A$. officinalis plants were used. Fully expanded leaves were chosen to make approximately $6 \mathrm{~mm}$ diameter leaf-discs. For drought treatment, the leaf-discs were placed on silica beads in a petri dish and dried in a laminar air flow. For ABA treatment, the leaf-discs were incubated in $2 \mu \mathrm{M}$ ABA while for salt treatment leaf-discs were incubated in $200 \mathrm{mM} \mathrm{NaCl}$. Water-treated leaf-discs were used as the control. Leaf-discs were vacuum infiltrated for $5 \mathrm{~min}$ in their respective treatment solutions before they were incubated to various time periods. The duration of treatments was $30 \mathrm{~min}$, one and two hours for the leaf-disc experiment.

\section{qRT-PCR analysis}

Expression analysis was performed by qRT-PCR for several genes including $A o D H N 1$. Reactions were performed on cDNA, prepared from various $A$. officinalis tissues. Total RNA was isolated using 'RNeasy Plant Kit' (QIAGEN). cDNA was prepared using 'MAXIMA First Strand cDNA Synthesis Kit' (Fermentas). 
Reaction was performed with 'KAPA SYBR FAST qPCR Kit' (KAPA Biosystems) using the 'StepOne ${ }^{\text {mit }}$ RealTime PCR Systems' (Applied Biosystems). All qRT-PCR data were generated from three independent biological replicates, each with three technical replicates $(n=3)$. Relative quantification of expression was determined using 'StepOne Software' (v2.1). Primers were designed using NCBI web-tool (http://www.ncbi.nlm.nih.gov/tools/ primer-blast/) and the list of SH qRT-PCR primers have been provided in Additional file 3. Constitutively expressed Ubiquitin 10 was used as internal control and the primer sequences were 5'-CGCCGGCAAGCAGCTAGAGG -3 (forward) and 5'-ACCACGGAGCCTGAGGACCA-3' (reverse) for Ubiquitin 10 (AT4G05320) (250 bp). The primer sequences used to amplify AoDHN1 are 5'-GACACCACTGGAGCGT-3' (forward) 5' -TCCGTAGTTCCGTACC-3' (reverse).

\section{In situ hybridization}

In situ hybridization was carried out using leaf sections obtained from two-month-old green-house grown-plants following a published protocol [67] with minor modifications. For sense and anti-sense DIG-labeled RNA probe synthesis, the pGEM-T Easy vector (Promega) containing RT-PCR-amplified inserts using (5'-ATGTCAGAGTAC GGCGA-3' (forward) and 5'-ATGGTGGCCTCCGGG CA-3' (reverse) primers were linearized and in vitro transcribed using DIG-RNA Labeling Kit (Roche). Representative photographs are shown from at least five independent replicates examined.

\section{Sub-cellular localization of $A o D H N 1$ in Arabidopsis mesophyll protoplasts}

The coding region of $A o D H N 1$ was amplified using 5' -CTCGAGATGTCAGAGTACGGCGA-3' (forward) and 5 -CCCGGGATGGTGGCCTCCGGGCA-3' (reverse) primers with XhoI and SmaI restriction sites cloned into pGreen (HY105 backbone) containing mGFP (cloned with SpeI and XbaI), to generate $p$ Green-35S::AoDHN1GFP. Also, pPLVO6 UBI::NLS $S_{S V 40}-Y F P$ was used as the nuclear marker [68].

Leaf mesophyll protoplasts were isolated from 3- to 4week-old wild-type Arabidopsis thaliana (Col-0) plants [69] and transfected using $20 \mu \mathrm{g}$ of plasmid DNA each (pGreen-35S::AoDHN1-GFP and pPLVO6 UBI::NLS $S_{S V 40^{-}}$ $Y F P)$. Images were acquired $12 \mathrm{~h}$ to16h after transfection using a Carl Zeiss Axiovert $200 \mathrm{M}$ confocal laser scanning microscope ("http://www.zeiss/de/axiovert200.) with excitation at $488 \mathrm{~nm}$ (for GFP) and $514 \mathrm{~nm}$ (for YFP). Images of the signals obtained from protoplasts were determined using Zen 2012 SP2 software from Carl Ziess (Representative photographs are shown from at least eight independent protoplasts).

\section{Southern blotting}

Genomic DNA was extracted from Avicennia officinalis leaves by CTAB method [70] and was digested with restriction enzymes (EcoRI, HindIII and KpnI). Full length probe was amplified using the 5'-ATGTCAGAG TACGGCGA-3' (forward) and 5'-ATGGTGGCCTCCG GGCA-3' (reverse) primers. AoDHN1 probes were synthesized using Roche PCR DIG labelling kit. Southern blot was carried out following manufacturer's protocol (http://www.roche-applied-science.com).

\section{Functional assay of AoDHN1 in E. coli}

The coding region of AoDHN1 was amplified using 5'-GATCCATGTCAGAGTACGGCGA-3' (forward) and 5 '-CTCGAGTTAATGGTGGCCTCCGGG-3' (reverse) primers with BamHI and XhoI restriction sites. It was cloned into the over-expression vector $p G E X-6 P-1$ containing GST tag, to generate the AoDHN1-GST fusion construct. This fusion plasmid was introduced into $E$. coli BL21 cells by heat shock method. The transformed BL21 cells were first grown to log phase as determined by $\mathrm{OD}_{600}=0.5$. Equal volume of these cultures were transferred to sterile culture tubes with $10 \mathrm{ml}$ of LB medium containing $100 \mu \mathrm{g} / \mathrm{ml}$ ampicillin, $1 \mathrm{mM}$ IPTG (final concentration) with varying $\mathrm{NaCl}$ and PEG concentrations (Additional file 4 and Additional file 5). Finally, growth assay with $400 \mathrm{mM} \mathrm{NaCl}, 10 \%$ PEG (PEG 4000) and $500 \mathrm{mM}$ mannitol treatments (final concentration) were carried out. The cells were allowed to grow at $37^{\circ} \mathrm{C}$ and the growth was monitored at $\mathrm{OD}_{600}$ at specific time points.

\section{Additional files}

Additional file 1: Expression analysis of ESTs with less than twofold
difference in expression or with higher expression in the mesophyll
tissue. (A) qRT-PCR analysis of ESTs that showed less than twofold
difference in expression in salt gland-rich tissue compared to mesophyll
tissue. NAC domain containing protein 32 (NAC), Ubiquitin conjugating
enzyme 2 (UC2), Serine/Threonine-protein kinase (ST), Casein kinase (CK2),
Xylem Cysteine Peptidase 2 (XCP2), Transcription factor HBP1b (HBP), Trypsin
family protein (T), Phospholipase D (PD), Serine/Arginine-rich protein
spicing factor 34b (SA), Syringolide-induced protein 19-1-5 (SIP), Trehalose
6-phosphate synthase S6 (TPS). (B) qRT-PCR analysis of ESTs that showed
less expression in salt gland-rich tissue than in mesophyll tissue.
Mitochondrial Rho GTPase (MR), Plasma membrane H+ ATPase (HATPase),
Salt-inducible Zinc Finger 2 (ZF2), Vacular ATP synthase subunit D (VATD),
Auxin signalling F-box 2 (AF2), Peroxidase (PS), Glutamate synthase (GS),
Protein translation factor SUI1 homolog (PTF), 26S protein regulatory subunit 4
homolog (PRS), Disease resistance (DR), AP2 domain containing transcription
factor (AP2), Cytochrome -C Oxidase (CCO), Arginine decarboxylase (AD).
Data are mean \pm SE ( $=3$ ). RQ - Relative quantification.
Additional file 2: Secondary structure of AoDHN1, AoDHN2 and
AmDHN1. Secondary structure of the dehydrins was predicted using
PSIPRED (http://bioinf.CS.uCl.ac.uk/psipred/). All the three dehydrins (A)
AoDHN1 (B) AmDHN1 (C) AoDHN2 predominantly showed intrinsically
unstructured portion in the protein except two a-helices at the two K
segments towards the C-terminus.

Additional file 1: Expression analysis of ESTs with less than twofold difference in expression or with higher expression in the mesophyll tissue. (A) qRT-PCR analysis of ESTs that showed less than twofold difference in expression in salt gland-rich tissue compared to mesophyll tissue. NAC domain containing protein 32 (NAC), Ubiquitin conjugating enzyme 2 (UC2), Serine/Threonine-protein kinase (ST), Casein kinase (CK2), Xylem Cysteine Peptidase 2 (XCP2), Transcription factor HBP1b (HBP), Trypsin family protein $(T)$, Phospholipase D (PD), Serine/Arginine-rich protein spicing factor 34b (SA), Syringolide-induced protein 19-1-5 (SIP), Trehalose less expression in salt gland-rich tissue than in mesophyll tissue. Mitochondrial Rho GTPase (MR), Plasma membrane $H^{+}$ATPase (HATPase), Salt-inducible Zinc Finger 2 (ZF2), Vacular ATP synthase subunit D (VATD), Auxin signalling F-box 2 (AF2), Peroxidase (PS), Glutamate synthase (GS), Protein translation factor SUI1 homolog (PTF), 265 protein regulatory subunit 4 homolog (PRS), Disease resistance (DR), AP2 domain containing transcription factor (AP2), Cytochrome -C Oxidase (CCO), Arginine decarboxylase (AD). Data are mean \pm SE $(n=3)$. RQ - Relative quantification. segments towards the C-terminus. 
Additional file 3: List of primers used for qRT-PCR analysis and cloning of AoDHN1. qRT-PCR primers were designed using NCBI primer design web-tool (http://www.ncbi.nlm.nih.gov/tools/primer-blast/) for 34 ESTs that were identified from SH.

Additional file 4: Effect of different salt concentrations on growth of E. coli cells expressing AoDHN1. Differences in cell densities of E. coli cells expressing AoDHN1 and control E. coli cells when subjected to varying $\mathrm{NaCl}$ concentrations over a period of time (A) $200 \mathrm{mM} \mathrm{NaCl}$ treatment (B) $300 \mathrm{mM} \mathrm{NaCl}$ treatment (C) $400 \mathrm{mM} \mathrm{NaCl}$ treatment and (D) $500 \mathrm{mM} \mathrm{NaCl}$ treatment. E. coli cells expressing AoDHN1 showed a significant increase in cell density compared to control cells without AoDHN1. Treatment with $400 \mathrm{mM} \mathrm{NaCl}$ showed significant difference in the cell densities of $E$. coli cells and this concentration of $\mathrm{NaCl}$ was chosen for detailed analysis. Data are mean \pm SE $(n=3)$. Asterisks indicate a significant difference in cell densities as indicated by Student's $t$-test $(p<0.05)$. OD - Optical Density.

\section{Additional file 5: Effect of different concentrations of PEG on} growth of $E$. coli cells expressing AoDHN1. Differences in cell densities of E. coli cells expressing AoDHN1 and control E. coli cells when subjected to varying PEG concentrations over a period of time (A) 5\% PEG treatment (B) 10\% PEG treatment (C) 15\% PEG treatment and (D) 20\% PEG treatment. E. coli cells expressing AoDHN1 showed a significant increase in cell density compared to control cells without AoDHN1. Treatment with 10\% PEG showed significant difference in the cell densities of $E$. coli cells and this concentration of PEG treatment was chosen for detailed analysis. Data are mean $\pm \operatorname{SE}(n=3)$. Asterisks indicate a significant difference in cell densities as indicated by Student's $t$-test $(p<0.05)$. OD - Optical Density.

\section{Abbreviations}

SH: Subtractive hybridization; ESTs: Expressed sequence tags; qRT-PCR: Quantitative real-time PCR; AoDHN1: Avicennia officinalis Dehydrin 1; RACE: Rapid amplification of cDNA ends; REVIGO: REduce VIsualize gene ontology; ABA: Abscisic acid; GO: Gene ontology; NLS: Nuclear localization sequence; LEA protein: Late embryogenesis abundant protein; IPTG: Isopropyl $\beta$-D-1-thiogalactopyranoside; PEG: Poly ethylene glycol; GFP: Green fluorescence protein; YPF: Yellow fluorescence protein.

\section{Competing interests}

The authors declare that they have no competing interests.

\section{Authors' contributions}

PAJ designed and performed all experiments, including all statistical and bioinformatics analyses and wrote the manuscript. BM and EW performed the SH data clean-up and gene annotation. TML, QL and CSL participated in designing the project. PPK was responsible for overall supervision of experimental design, data analysis, and writing the manuscript. All authors approved the final manuscript.

\section{Acknowledgements}

This research was supported by the Singapore National Research Foundation under its Environmental \& Water Technologies Strategic Research Programme and administered by the Environment \& Water Industry Programme Office (EWI) of the PUB, Singapore, NRF-EWI-IRIS (2P 10004/81) (R-706-000-010-272). We also acknowledge the financial support from the Singapore-Peking-Oxford Research Enterprise, National University of Singapore. We acknowledge the Keppel Club and NParks Singapore for granting us permission to collect the mangrove samples from Berlayer Creek and Sungei Buloh Wetland Reserves (NP/RP1 2-002-1). Authors also acknowledge Dr. Xu Jian for providing NLS SV40 - YFP vector, and Dr. Pannaga Krishnamurthy for critically reviewing the manuscript.

\section{Author details}

'Department of Biological Sciences, National University of Singapore, 14 Science Drive 4, Singapore, Republic of Singapore. ${ }^{2}$ NUS Environmental Research Institute (NERI), National University of Singapore, \#02-01, T-Lab Building, 5A Engineering Drive 1, Singapore, Republic of Singapore. ${ }^{3}$ Department of Chemical and Biomolecular Engineering, National University of Singapore, Singapore, Republic of Singapore. ${ }^{4}$ IFReC, Osaka University, 3-1 Yamada-oka, Suita, Osaka 565-0871, Japan. ${ }^{5}$ Temasek Life Sciences
Laboratory, National University of Singapore, 1 Research Link, Singapore, Republic of Singapore.

Received: 4 August 2014 Accepted: 15 October 2014

Published online: 18 November 2014

\section{References}

1. Tomlinson BP: The Botany of Mangroves. Cambridge: Cambridge University Press; 1986.

2. Cardale S, Field CD: The structure of the salt gland of Aegiceras corniculatum. Planta 1971, 99(3):183-191.

3. Boon P, Allaway W: Rates and ionic specificity of salt secretion from excised leaves of the mangrove, Avicennia marina (Forsk.) Vierh. Aquatic Bot 1986, 26:143-153.

4. Thomson W, Faraday C, Oross JW: Salt Glands. In Solute Transport in Plant Cells and Tissues. Edited by Baker DA, Hall JL. England: Longman Scientific and Technical; 1988.

5. Balsamo RA, Thomson WW: Ultrastructural features associated with secretion in the salt glands of Frankenia grandifolia (Frankeniaceae) and Avicennia germinans (Avicenniaceae). Am J Bot 1993, 80(11):1276-1283.

6. Shimony C, Fahn A, Reinhold L: Ultrastructure and ion gradients in the salt glands of Avicennia marina (Forssk.) Vierh. New Phytol 1973, 72:27-36.

7. Campbell N, Thomson WW: The ultrastructure of Frankenia salt glands. Ann Bot 1976, 40(4):681-686.

8. Kathiresan K, Bingham BL: Biology of Mangroves and Mangrove Ecosystems. In Advances in Marine Biology, Volume 40. San Diego: Academic Press; 2001:81-251.

9. Tan W-K, Lin Q, Lim T-M, Kumar P, Loh C-S: Dynamic secretion changes in the salt glands of the mangrove tree species Avicennia officinalis in response to a changing saline environment. Plant Cell Environ 2013, 36(8):1410-1422

10. Dschida W, Platt-Aloia K, Thomson W: Epidermal peels of Avicennia germinans (L.) Stearn: a useful system to study the function of salt glands. Ann Bot 1992, 70(6):501-509.

11. Chen J, Xiao Q, Wu F, Dong X, He J, Pei Z, Zheng H: Nitric oxide enhances salt secretion and $\mathrm{Na}^{+}$sequestration in a mangrove plant, Avicennia marina, through increasing the expression of $\mathrm{H}^{+}$-ATPase and $\mathrm{Na}^{+} / \mathrm{H}^{+}$ antiporter under high salinity. Tree Physiol 2010, 30(12):1570-1585.

12. Drennan PM, Berjak P, Lawton JR, Pammenter N: Ultrastructure of the salt glands of the mangrove, Avicennia marina (Forssk.) Vierh., as indicated by the use of selective membrane staining. Planta 1987, 172:176-183.

13. Ding F, Yang J-C, Yuan F, Wang B-S: Progress in mechanism of salt excretion in recretohalopytes. Front Biol 2010, 5(2):164-170.

14. Schneeberger K, Weigel D: Fast-forward genetics enabled by new sequencing technologies. Trends Plant Sci 2011, 16(5):282-288.

15. Vuylsteke M, Peleman JD, van Eijk MJT: AFLP-based transcript profiling (cDNA-AFLP) for genome-wide expression analysis. Nat Protoc 2007, 2(6):1399-1413.

16. Liang P, Pardee A: Differential display of eukaryotic messenger RNA by means of the polymerase chain reaction. Science 1992, 257(5072):967-971.

17. Metzker ML: Applications of next-generation sequencing. Nat Rev Genet 2010, 11(1):31-46.

18. Zhang $J-Z$, Gao W, Yang H-B, Zhang B, Zhu Z-Y, Xue Y-F: Screening for genes essential for mouse embryonic stem cell self-renewal using a subtractive RNA interference library. Stem Cells 2006, 24(12):2661-2668

19. Lukyanov S, Rebrikov D, Buzdin A: Suppression Subtractive Hybridization. In Nucleic Acids Hybridization Modern Applications. Edited by Buzdin A, Lukyanov S. Netherlands: Springer; 2007:53-84.

20. Diatchenko L, Lau YF, Campbell AP, Chenchik A, Mogadam F, Huang B, Lukyanov S, Lukyanov K, Gurskaya N, Sverdlov ED, Siebert PD: Suppression subtractive hybridization: a method for generating differentially regulated or tissue-specific CDNA probes and libraries. Proc Natl Acad Sci U S A 1996, 93(12):6025-6030.

21. Xie W, Yang $X$, Wang $S I$, Wu QJ, Yang NN, Li RM, Jiao XG, Pan HP, Liu BM, Feng YT, Xu BY, Zhou XG, Zhang YJ: Gene expression profiling in the thiamethoxam resistant and susceptible B-biotype sweetpotato whitefly, Bemisia tabaci. J Insect Sci 2012, 12(46):1-14. 
22. Chen S, Zhou R, Huang Y, Zhang M, Yang G, Zhong C, Shi S: Transcriptome sequencing of a highly salt tolerant mangrove species Sonneratia alba using Illumina platform. Mar Genomics 2011, 4(2):129-136.

23. Huang J, Lu X, Yan H, Chen S, Zhang W, Huang R, Zheng Y: Transcriptome characterization and sequencing-based identification of salt-responsive genes in Millettia pinnata, a semi-mangrove plant. DNA Res 2012, 19(2):195-207.

24. Yamanaka T, Miyama M, Tada Y: Transcriptome profiling of the mangrove plant Bruguiera gymnorhiza and identification of salt tolerance genes by Agrobacterium functional screening. Biosci Biotechnol Biochem 2009, 73(2):304-310.

25. Tan W-K, Lim T-M, Loh C-S: A simple, rapid method to isolate salt glands for three-dimensional visualization, fluorescence imaging and cytological studies. Plant Meth 2010, 6(1):24.

26. Tuteja N: Mechanisms of high salinity tolerance in plants. Meth Enzymol 2007, 428:419-457.

27. Cushman JC: Osmoregulation in plants: Implications for agriculture. Am Zoo 2001, 41(4):758-769.

28. Ma S: Dissecting salt stress pathways. J Exp Bot 2006, 57:1097-1107.

29. Hanin M, Brini F, Ebel C, Toda Y, Takeda S, Masmoudi K: Plant dehydrins and stress tolerance: versatile proteins for complex mechanisms. Plant Sig Behav 2011, 6(10):1503-1509.

30. Xiong L, Zhu JK: Molecular and genetic aspects of plant responses to osmotic stress. Plant Cell Environ 2002, 25(2):131-139.

31. Campbell SA, Close TJ: Dehydrins: genes, proteins, and associations with phenotypic traits. New Phytol 1997, 137(1):61-74.

32. Close T, Kortt A, Chandler P: A cDNA-based comparison of dehydrationinduced proteins (dehydrins) in barley and corn. Plant Mol Biol 1989, 13(1):95-108.

33. Rorat T: Plant dehydrins - Tissue location, structure and function. Cell Mol Biol Lett 2006, 11(4):536-556.

34. Cuming AC: LEA Proteins. In Seed Proteins. Edited by Shewry PR, Casey R. Dordrecht, The Netherlands: Kluwer Academic Publishers; 1999:753-780.

35. Flowers TJ, Colmer TD: Salinity tolerance in halophytes. New Phytol 2008, 179(4):945-963.

36. Battaglia M, Olvera-Carrillo Y, Garciarrubio A, Campos F, Covarrubias AA: The enigmatic LEA proteins and other hydrophilins. Plant Physio/ 2008, 148(1):6-24.

37. Mehta PA, Rebala KC, Venkataraman G, Parida A: A diurnally regulated dehydrin from Avicennia marina that shows nucleo-cytoplasmic localization and is phosphorylated by Casein kinase II in vitro. Plant Physiol Biochem 2009, 47(8):701-709.

38. Supek F, Bosnjak M, Skunca N, Smuc T: REVIGO summarizes and visualizes longlists of gene ontology terms. PLoS One 2011, 6(7):e21800.

39. Kylin A, Gee R: Adenosine Triphosphatase activities in leaves of the mangrove Avicennia nitida Jacq influence of sodium to potassium ratios and salt concentrations. Plant Physiol 1970, 45(2):169-172.

40. Dassanayake M, Haas J, Bohnert H, Cheeseman J: Comparative transcriptomics for mangrove species: an expanding resource. Funct Integr Genomics 2010, 10(4):523-532

41. Fu X, Huang Y, Deng S, Zhou R, Yang G, Ni X, Li W, Shi S: Construction of a SSH library of Aegiceras corniculatum under salt stress and expression analysis of four transcripts. Plant Sci 2005, 169(1):147-154.

42. Li L, Wang W-q, Wu C-x, Han T-f, Hou W-s: Construction of two suppression subtractive hybridization libraries and identification of salt-induced genes in soybean. J Integr Agric 2012, 11(7):1075-1085

43. Wong $Y-Y, H o$ C-L, Nguyen PD, Teo S-S, Harikrishna JA, Rahim RA, Wong MCVL: Isolation of salinity tolerant genes from the mangrove plant, Bruguiera cylindrica by using suppression subtractive hybridization (SSH) and bacterial functional screening. Aquatic Bot 2007, 86(2):117-122.

44. Osakabe Y, Yamaguchi-Shinozaki K, Shinozaki K, Tran L-SP: Sensing the environment: key roles of membrane-localized kinases in plant perception and response to abiotic stress. J Exp Bot 2013, 64(2):445-458.

45. Ukitsu H, Kuromori T, Toyooka K, Goto Y, Matsuoka K, Sakuradani E, Shimizu S, Kamiya A, Imura Y, Yuguchi M, Wada T, Hirayama T, Shinozaki K: Cytological and biochemical analysis of COF1, an Arabidopsis mutant of an ABC transporter gene. Plant Cell Physiol 2007, 48(11):1524-1533.

46. Lian H-L, Yu X, Ye Q, Ding X-S, Kitagawa Y, Kwak S-S, Su W-A, Tang Z-C: The Role of aquaporin RWC3 in drought avoidance in rice. Plant Cell Physiol 2004, 45(4):481-489.
47. Baena-González E, Sheen J: Convergent energy and stress signaling. Trends Plant Sci 2008, 13(9):474-482.

48. Grudkowska M, Zagdańska B: Multifunctional role of plant cysteine proteinases. Acta Biochim Pol 2004, 51(3):609-624.

49. Li B, Sang T, He L, Sun J, Li J, Guo S: Exogenous spermidine inhibits ethylene production in leaves of cucumber seedlings under $\mathrm{NaCl}$ stress. J Am Soc Hort Sci 2013, 138(2):108-113.

50. Yang J, Kloepper JW, Ryu C-M: Rhizosphere bacteria help plants tolerate abiotic stress. Trends Plant Sci 2009, 14(1):1-4.

51. Lockhart J: Salt of the earth: ethylene promotes salt tolerance by enhancing $\mathrm{Na}^{+} / \mathrm{K}^{+}$homeostasis. Plant Cell 2013, 25(9):3150.

52. Dyson HJ, Wright PE: Intrinsically unstructured proteins and their functions. Nat Rev Mol Cell Biol 2005, 6(3):197-208.

53. Hundertmark M, Hincha D: LEA (Late Embryogenesis Abundant) proteins and their encoding genes in Arabidopsis thaliana. BMC Genomics 2008, 9(1):118

54. Ismail AM, Hall AE, Close TJ: Allelic variation of a dehydrin gene cosegregates with chilling tolerance during seedling emergence. Proc Natl Acad Sci 1999, 96(23):13566-13570.

55. Nylander M, Svensson J, Palva ET, Welin B: Stress-induced accumulation and tissue-specific localization of dehydrins in Arabidopsis thaliana. Plant Mol Biol 2001, 45(3):263-279.

56. Close TJ: Dehydrins: emergence of a biochemical role of a family of plant dehydration proteins. Physiol Planta 1996, 97(4):795-803.

57. Goday A, Jensen AB, Culiáñez-Macià FA, Mar Albà M, Figueras M, Serratosa J, Torrent $M$, Pagès M: The maize abscisic acid-responsive protein Rab17 is located in the nucleus and interacts with nuclear localization signals. Plant Cell 1994, 6(3):351-360.

58. Allagulova CR, Gimalov F, Shakirova F, Vakhitov V: The plant dehydrins: structure and putative functions. Biochem Mosc 2003, 68(9):945-951.

59. Ismail FA, Nitsch LM, Wolters-Arts MM, Mariani C, Derksen JW: Semi-viviparous embryo development and dehydrin expression in the mangrove Rhizophora mucronata Lam. Sex Plant Reprod 2010, 23(2):95-103.

60. Reyes JL, Rodrigo M-J, Colmenero-Flores JM, Gil J-V, Garay-Arroyo A, Campos F, Salamini F, Bartels D, Covarrubias AA: Hydrophilins from distant organisms can protect enzymatic activities from water limitation effects in vitro. Plant Cell Environ 2005, 28(6):709-718.

61. Karlson DT, Fujino T, Kimura S, Baba K, Itoh T, Ashworth EN: Novel plasmodesmata association of dehydrin-like proteins in cold-acclimated red-osier dogwood (Cornus sericea). Tree Physiol 2003, 23(11):759-767.

62. Mundy J, Chua N-H: Abscisic acid and water-stress induce the expression of a novel rice gene. EMBO J 1988, 7(8):2279.

63. Stanca A, Crosatti C, Grossi M, Lacerenza N, Rizza F, Cattivelli L: Molecular adaptation of barley to cold and drought conditions. Euphytica 1996, 92(1-2):215-219.

64. Giordani T, Natali L, D'Ercole A, Pugliesi C, Fambrini M, Vernieri P, Vitagliano C, Cavallini A: Expression of a dehydrin gene during embryo development and drought stress in ABA-deficient mutants of sunflower (Helianthus annuus L.). Plant Mol Biol 1999, 39(4):739-748.

65. Houde M, Daniel C, Lachapelle M, Allard F, Laliberté S, Sarhan F: Immunolocalization of freezing-tolerance-associated proteins in the cytoplasm and nucleoplasm of wheat crown tissues. Plant J 1995, 8(4):583-593.

66. Altschul SF, Gish W, Miller W, Myers EW, Lipman DJ: Basic local alignment search tool. J Mol Biol 1990, 215(3):403-410.

67. Jackson D: In Situ Hybridisation in Plants. In Molecular Plant Pathology, A Practical Approach. Edited by Bowles DJ, Gurr SJ, McPherson M. U.K: Oxford University Press; 1991:163-174.

68. Kalderon D, Roberts BL, Richardson WD, Smith AE: A short amino acid sequence able to specify nuclear location. Cell 1984, 39(3):499-509.

69. Yoo S-D, Cho Y-H, Sheen J: Arabidopsis mesophyll protoplasts: a versatile cell system for transient gene expression analysis. Nat Protoc 2007, 2(7):1565-1572.

70. Doyle JJ: A rapid DNA isolation procedure for small quantities of fresh leaf tissue. Phytochem Bull 1987, 19:11-15

\section{doi:10.1186/s12870-014-0291-6}

Cite this article as: Jyothi-Prakash et al.: Identification of salt glandassociated genes and characterization of a dehydrin from the salt secretor mangrove Avicennia officinalis. BMC Plant Biology 2014 14:291. 